\title{
Особливості використання засобів дистанційного навчання в закладах вищої освіти фізкультурного профілю в умовах карантинних обмежень
}

\begin{abstract}
Олена Басенко Ірина Алексєєва Яна Алексєнко Яна Жерновнікова
\end{abstract}

Харківська державна академія фізичної культури, Харків, Україна

Мета: проаналізувати організаційні та методичні особливості використання інформаційних засобів дистанційного навчання у підготовці майбутніх фахівців фізичної культури та спорту.

Матеріал і методи: для реалізації поставленої мети нами були використані такі методи дослідження: аналіз науково-методичної літератури; ресурси мережі Інтернет; опитування за допомогою Google-форми; аналіз, синтез та узагальнення отриманих даних; методи математичної статистики. В опитуванні брали учать 93 студенти першого, другого та третього курсів денної форми навчання Харківської держаної академії фізичної культури.

Результати: розглянуто особливості організації навчального процесу в умовах карантинних обмежень з використанням засобів дистанційного навчання у закладах вищої освіти фізкультурного профілю. Проведено онлайнопитування студентів, яке виявило їх ставлення до дистанційної, очної і змішаної форм навчання; їх вподобання та забезпеченість різними електронними ресурсами, програмами, інструментами інформаційних комунікацій, які використовувалися викладачами в навчальному процесі. Проаналізовано можливі складнощі і значимість для здобувачів освіти переваг дистанційного навчання.

Висновки: дослідження показало, що викладачі академії за короткий термін та у складних умовах освоїли цифрові інструменти, комунікаційні ресурси та дистанційні платформи, які не використовували раніше. Онлайн-опитування студентів виявило неодностайність їх ставлення до дистанційної, очної і змішаної форм навчання. Результати дослідження підтвердили думку інших вчених про те, що дистанційне навчання, як альтернативна форма освітнього процесу, не може в повній мірі замінити традиційну очну форму навчання, а використання засобів дистанційного навчання дозволяє урізноманітнити освітній процес, зробити його значно цікавішим та ефективнішим.

Ключові слова: дистанційне навчання, студенти, онлайн-заняття, засоби дистанційного навчання, програми для відеоконференцій, інструменти електронного навчання.

\section{Вступ}

Пандемія COVID-19 та карантинні обмеження в останні роки торкнулися практично всіх сфер життєдіяльності населення більшості держав світу і навчили усіх без винятку жити по-новому. Такий виклик планетарного масштабу розпочав значні соціальні зрушення до адаптації до нової реальності.

Сферу вищої освіти сміливо можна назвати однією з тих, на яку пандемія зробила найбільший вплив в глобальному масштабі. Хоча і виникли певні проблеми, вона стала однією з небагатьох, підготовлених до переведення більшості своїх процесів та ресурсів в онлайнформу. Для оперативної підтримки якості вищої освіти викладачами закладів було проведено величезну організаційну та методичну роботу, які в умовах обмеженого часу були вимушені не тільки навчати, а також і навчатися самим, запроваджувати різноманітні інноваційні освітні технології, зокрема різні засоби дистанційного навчання. Можливості засобів дистанційного навчання в сфері вищої освіти є значними і добре обґрунтованими за рахунок використання електронних технологій, які вже були накопичені в інформаційних ресурсах методичного забезпечення різних дисциплін [1, 5, 6, 10, 11].

В освітньому процесі студенти виконують не тільки роль споживачів, але і стейкхолдерів, індивідів, внесок яких $€$ підґрунтям успіху закладу вищої освіти. Вони в певній мірі впливають на його роботу. Це дозволяє здобувачу вищої освіти бути компетентним суб'єктом освітнього процесу, в тому числі суб'єктом оцінки його якості.

Питання дистанційного навчання з урахуванням досвіду роботи викладачів і студентів, що отримали розуміння і можливість порівняння особливостей проведення занять у звичайній та дистанційній формах є актуальними на сьогодні, потребують різностороннього вивчення та активного дискусійного розгляду.

Дистанційна освіта не є новим поняттям. В останні десятиліття швидко розвиваються її науково-методичні основи. Проблемам з питань розвитку дистанційної освіти присвячені роботи багатьох зарубіжних науковців, таких як: Р. Деллінг, Г. Рамблє, Д. Кіган, М. Сімонсон, М. Мур, А. Кларк, М. Томпсон і ін. та відповідно вітчизняних, таких як: В. Кухаренко, В. Олійник, В. Рибалко, О. 
Свєженцев, О. Андрєєв, Г. Козлакова, І. Козубовська, Є. Полат, А. Хуторський, І. Власенко, Г. Даценко та ін. Проблеми теорії та практики дистанційного навчання у галузі фізичної культури та спорту стали предметом дослідження у працях В. Шандригось, В. Ашаніна, Л. Філенко, О. Церковної, В. Мунтяна, С. Пятисоцької, М. Булатової, А. Осіпова, П. Ладика, М. Кудрявцева та ін [2-5, 9]. Але, не зважаючи на значну кількість наукових досліджень у даному напрямку, i, здавалося б, готових до дистанційної роботи закладів вищої освіти, не всі змогли оперативно та ефективно організувати процес онлайн-навчання. Низка спеціалістів на підставі стану дистанційної освіти зазначає актуальність потреби у ефективному навчанні, використанні різноманітних засобів дистанційного навчання, з огляду на можливу затребуваність комплексного навчання у майбутньому $[6,7,8]$.

Мета дослідження - проаналізувати організаційні та методичні особливості використання інформаційних засобів дистанційного навчання у підготовці майбутніх фахівців фізичної культури та спорту.

\section{Матеріал і методи дослідження}

Для реалізації поставленої мети нами були використані такі методи дослідження: аналіз науково-методичної літератури; ресурси мережі Інтернет; опитування за допомогою Google-форми; аналіз, синтез та узагальнення отриманих даних; методи математичної статистики. Дослідження проводилося на базі Харківської держаної академії фізичної культури. В опитуванні приймали учать 93 студенти першого, другого та третього курсів денної форми навчання.

\section{Результати дослідження}

За останні майже два роки у період карантинних обмежень здобувачі вищої освіти усіх навчальних закладів, зокрема Харківської державної академії фізичної культури, навчалися за різними формами навчання: дистанційною (онлайн), очною (традиційно в аудиторії), змішаною. Але все ж таки, більше часу навчання здійснювалося дистанційно.

О. Корбут визначає дистанційне навчання як сукупність технологій, що забезпечують доставку студентам основного обсягу навчального матеріалу, інтерактивну взаємодію студентів і викладачів у процесі навчання, надання студентам можливості самостійної роботи з навчальними матеріалами та засобами самооцінювання. У зв'язку з цим та спираючись на те, що дистанційна освіта - це відкрита система навчання, що передбачає активне спілкування між викладачем і студентом за допомогою сучасних технологій і мультимедіа, використання засобів дистанційного навчання є її основою невід'ємною частиною.

Для того, щоб проаналізувати особливості використання засобів дистанційного навчання та ефективність їх впровадження в освітній процес майбутніх фахівців фізичної культури та спорту було проведено онлайн-опитування з використанням Google-форми, в якому прийняли учать 93 студенти першого, другого та третього курсів Харківської державної академії фізичної культури. Були проаналізовані прихильності та вподобання студентів до різних форм навчання, недоліки викладання та труднощі, які виникли у навчальному процесі.

Для проведення занять в дистанційній формі використовувалися програми для відеоконференцій (для проведення лекційних, семінарських, практичних занять) та засоби електронного навчання (інструменти для надання матеріалів дисциплін, виконання практичних і самостійних робіт, зворотного зв'язку, оцінювання). Треба зазначити, що викладачам була надана можливість самим додатково обирати ті засоби дистанційного навчання, які були б для них найзручнішими, окрім системи дистанційного навчання Moodle (яка використовується в Харківській державній академії фізичної культури як основний засіб дистанційного навчання).

Для проведення онлайн-занять в режимі відеозв'яку викладачі використовували такі програми як Zoom, Google Meet, Microsoft Teams, Skype, Webex, BigBlueButton (рис. 1). Але, як видно з отриманих результатів, більшість викладачів використовували програми Zoom i Google Meet (відповідно 42 \%, 43 \%).

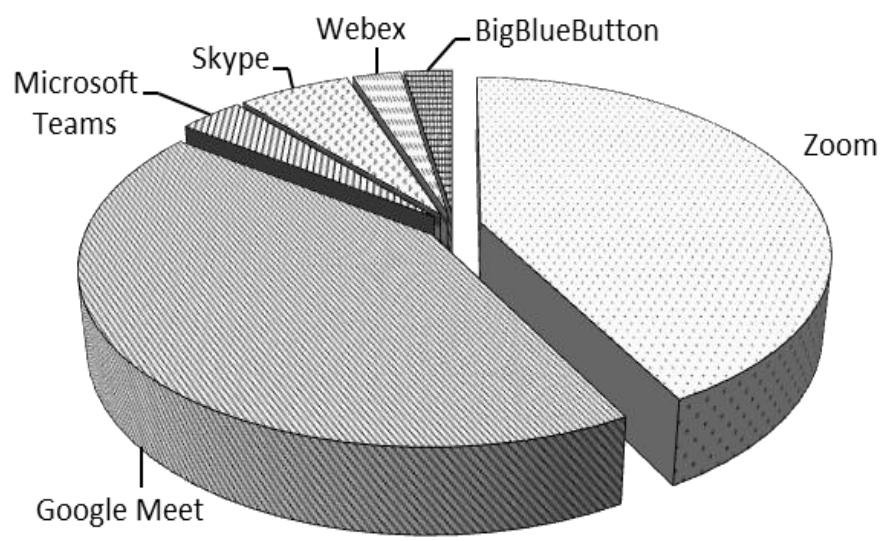

Рис. 1. Програми, які використовувалися для проведення онлайн-занять в режимі відеозв'язку

В анкетуванні студентам було запропоновано оцінити за 5-бальною шкалою на скільки вони задоволені використанням цих програм у дистанційному навчанні. На рис. 2 видно, що студентам більше до вподоби програмa Google Meet (55\% респондентів оцінили у 5 балів) ніж Zoom (5 балів - 28 \%). Зважаючи на це, можна порекомендувати викладачам використовувати для відеоконференцій програму Google Meet, щоб студенти почували себе більш комфортно і у них не виникало негативних почуттів до навчального процесу в онлайн режимі.

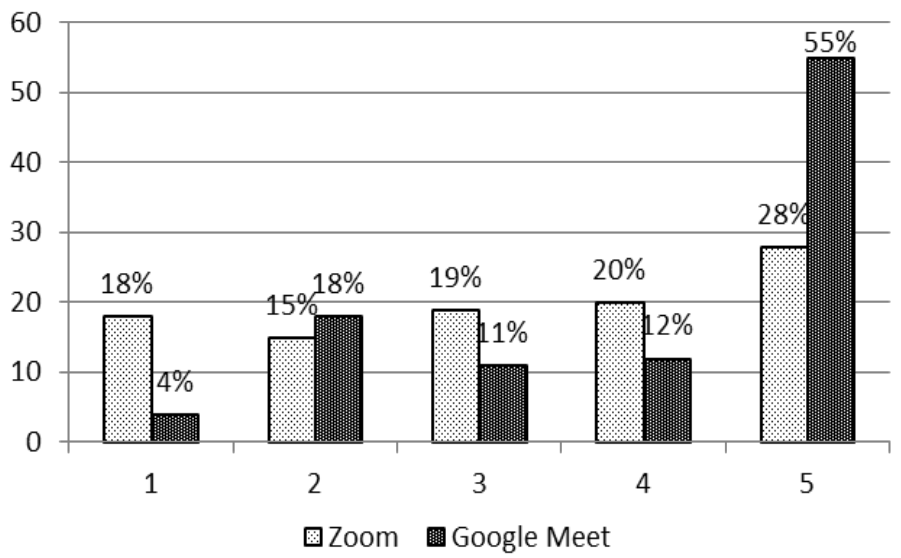

Рис. 2. Оцінка вподобань студентами програм Zoom i Google Meet за 5-бальною шкалою (1 - не задоволений, 5 - дуже задоволений) 


\section{СЛОБОЖАНСЬКИЙ НАУКОВО-СПОРТИВНИЙ ВІСНИК}

Крім програм для відеоконференцій та системи дистанційного навчання Moodle, для якісного навчального процесу, надання матеріалів дисциплін, виконання практичних і самостійних робіт, зворотного зв'язку та оцінювання, викладачами використовувалися такі вебдодатки та інструменти інформаційних комунікацій як: соціальні мережі, e-mail, Google Диск, Google Classroom та Microsoft Teams (рис. 3).

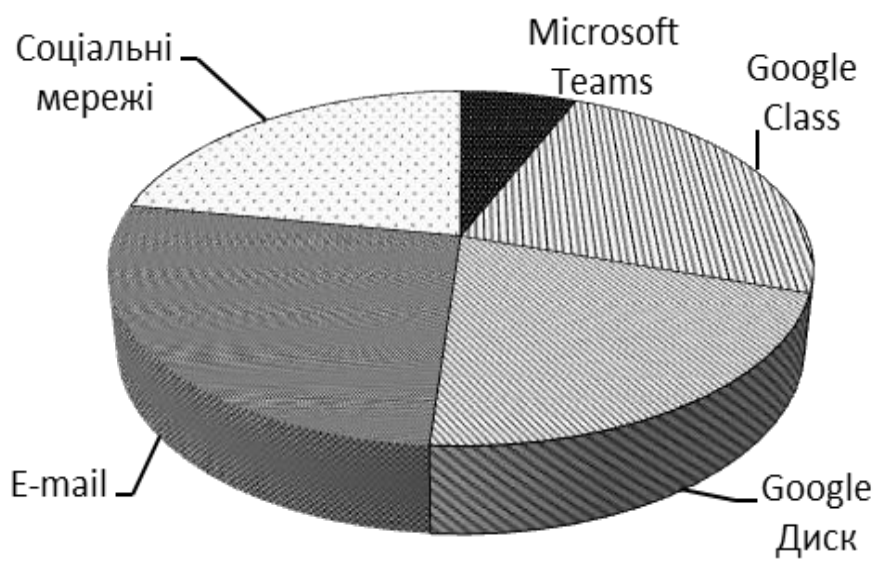

Рис. 3. Веб-додатки та інструменти інформаційних комунікацій, які використовувалися при дистанційному навчанні

Студентам було запропоновано виразити свою задоволеність цими програмами та оцінити їх використання у навчальному процесі за 5-бальною шкалою. На рис. 4 видно, що студентам більше до вподоби працювати у соціальних мережах (середня оцінка 4,1) як найбільш комфортних інформаційно-комунікаційних засобах дистанційного навчання для молоді, для яких спілкування у соціальних мережах є основною частиною їх повсякденності.

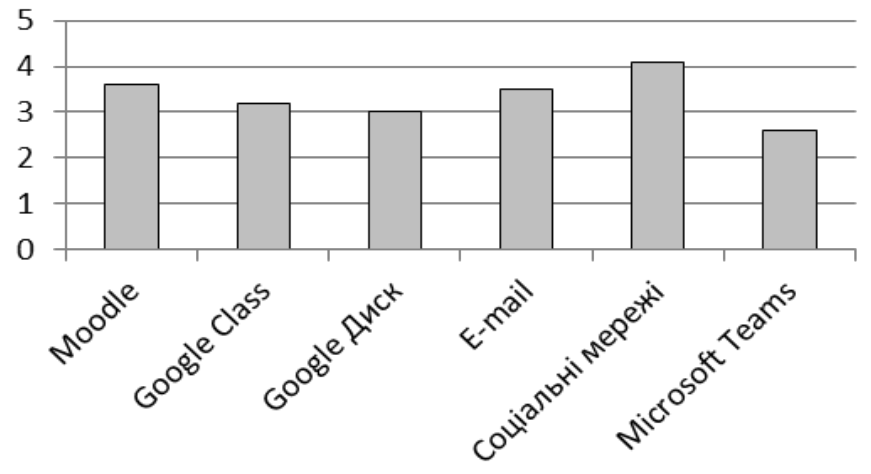

Рис. 4. Середня оцінка вподобань студентів щодо використання у навчальному процесі програм та інструментів інформаційних комунікацій за 5-бальною шкалою (1 - не задоволений, 5 - дуже задоволений)

На рис. 5 представлено відповіді (у відсотковому співвідношенні) на питання щодо виникнення можливих ускладнень під час дистанційного навчання. Було виявлено, що не зважаючи на те, що під час дистанційного навчання у більшості студентів виникали труднощі (62 \%), комунікація з викладачами (у системі викладачстудент) була достатньою (78 \%) та більшість студентів вказали, що навчальне навантаження не змінилося і не стало важче сприймати навчальний матеріал (відповідно $52 \%, 53 \%)$.

Також було виявлено, що здебільшого викладачі проводили заняття в режимі відеозв'язку (82 \%) та не завантажували студентів завданнями для самостійної роботи (15 \% від усього навчального навантаження), а деякі з них використовували елементи гейміфікації, що підвищувало пізнавальну активність до дисциплін та мотивацію до навчання.

Чи зросло навчальне навантаження під час дистанційного навчання?

Чи стало важче сприймати навчальний матеріал?

Чи виникали технічні труднощі під час дистанційного навчання?

Чи достатньою була комунікація з викладачами під час дистанційного навчання?

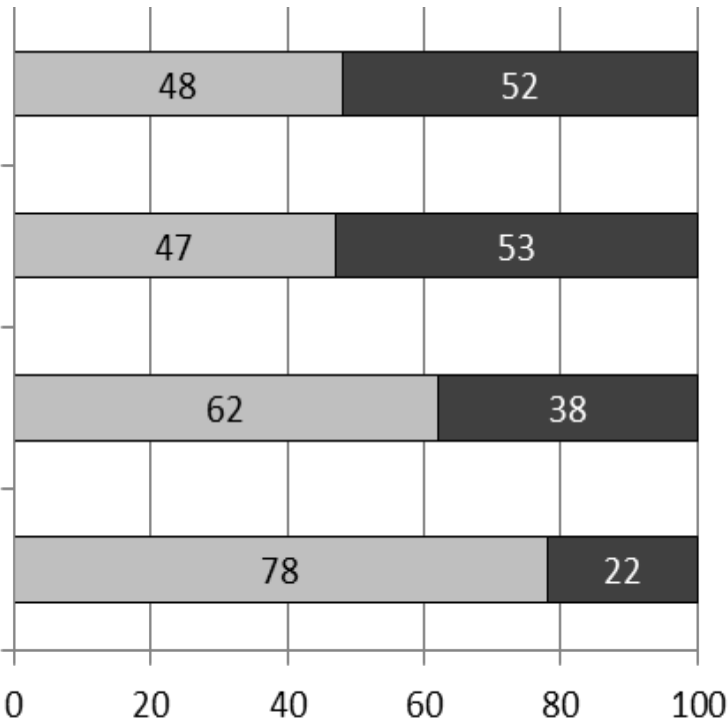

так, \% $\square$ ні, \%

Рис. 5. Відповіді на питання щодо можливих труднощів під час дистанційного навчання 


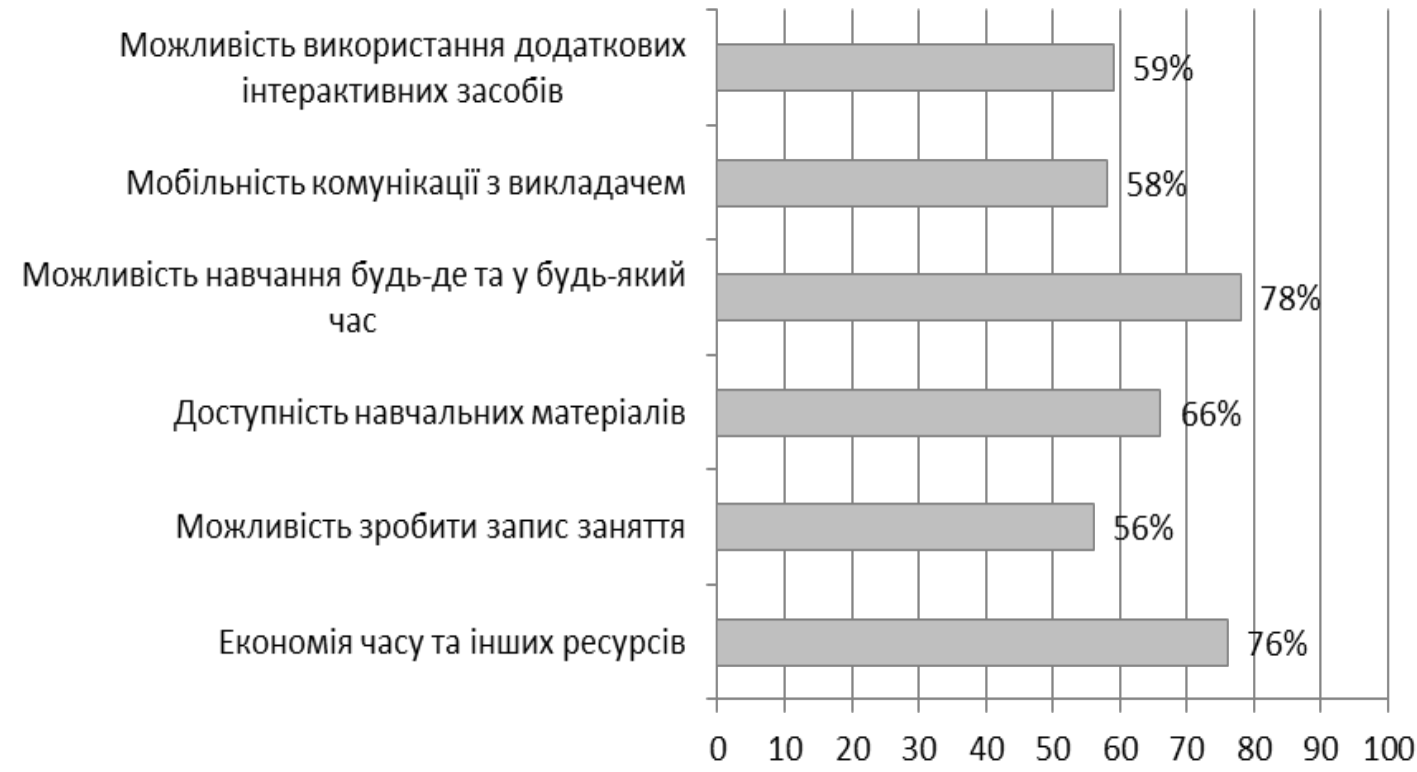

Рис. 6. Кількість студентів (\%), які оцінили на 4 і 5 за 5-бальною шкалою важливість для них переваг дистанційного навчання

На питання: «У якому форматі Вам було зручніше здавати заліки та іспити?» 53 \% студентів відповіли дистанційно (онлайн) та 47 \% - очно (в аудиторії).

Як показують дослідження, дистанційне навчання має низку переваг та недоліків [5, 7, 10, 11]. Нами були виділені такі переваги як: економія часу та інших ресурсів; можливість навчання будь-де та у будь-який час; мобільність комунікації з викладачем; доступність навчальних матеріалів; можливість зробити запис заняття; можливість використання додаткових інтерактивних засобів. Студентам було запропоновано оцінити важливість цих переваг дистанційного навчання саме для них за 5-бальною шкалою (де 1 - не важлива, 5 - дуже важлива).

На рис. 6 представлено кількість студентів, які оцінили важливість для них даних переваги на 4 та 5 балів. Як

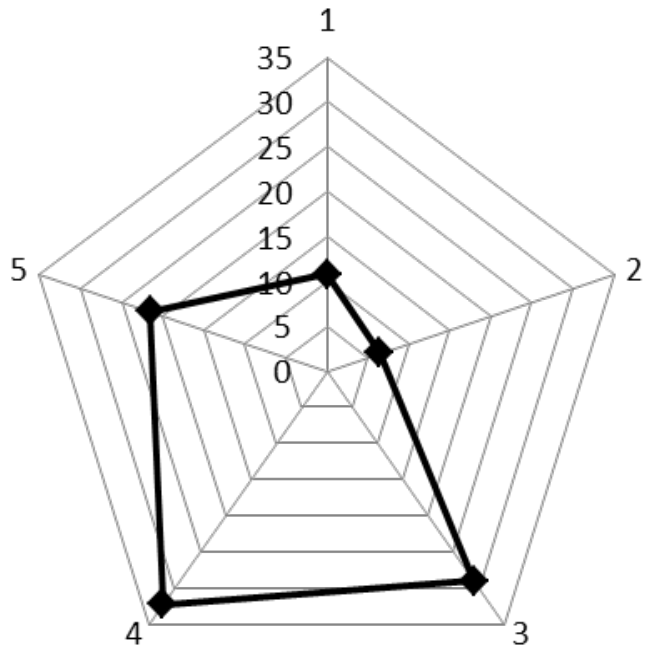

Рис. 7. Задоволеність студентів дистанційним навчанням за 5-бальною шкалою (1 - не задоволений, 5 - дуже задоволений) видно з графіку (рис. 6), найбільш важливим для студентів $€$ «можливість навчання будь-де та у будь-який час» (78 \%), що дає можливість економити час та інші ресурси (76 \%), а також «доступність навчальних матеріалів» (66\%).

Не зважаючи на труднощі, які виникали в процесі дистанційного навчання, більшість студентів осталися задоволені (рис. 7).

За результатами опитування було виявлено, що погляди студентів стосовно їх відношення до форм навчального процесу неодностайні. На питання «яка форма навчання вам більш до вподоби?» думки розділилися майже рівномірно (рис. 8): 36 \% обрали дистанційну форму навчання, 34 \% - змішану, 30 \% - очну (традиційно в аудиторіях).



Рис. 8. Вподобання студентів до різних форм навчання 


\section{СЛОБОЖАНСЬКИЙ НАУКОВО-СПОРТИВНИЙ ВІСНИК}

Результати дослідження показати, що дистанційна освіта є дієвим рішенням у багатьох життєвих ситуаціях, зокрема глобальної пандемії та в умовах карантинних обмежень. Але вона не $є$ найкращтм рішенням освітнього процесу. Дистанційне навчання може використовуватися у різних випадках і найчастіше у закладах вищої освіти фізкультурного профілю, де навчаються діючі спортсмени, які часто знаходяться на спортивних зборах та тренуваннях. Але дистанційна форма навчання може бути більш дієвим засобом ефективної освіти, який доповнює очну форму навчання та утворює змішану. А засоби дистанційного навчання надають можливість організувати повноцінний навчальний процес майбутніх фахівців фізичної культури та спорту.

\section{Висновки / Дискусія}

Треба зазначити, що багато сфер особистого, громадського та професійного життя не тільки змогли встояти, але й адаптуватися до нової реальності.

Отримані результати опитування здобувачів вищої освіти у сфері фізичної культури і спорту виявили неузгодженість вподобань щодо форм навчання, але вказують на зацікавленість студентів в дистанційному навчанні. Аналіз Інтернет-ресурсів та моніторинг якості дистанційної освіти Міністерства освіти і науки України показав позитивну динаміку в оцінці якості організації дистанційного навчання, порівняно з минулим роком. Це вказує на відкритість викладачів до підвищення кваліфікації у сфері інформаційних технологій, вдосконалення їх цифрової компетентності для ефективного впровадження інструментів дистанційного навчання в освітній процес.

Виявлено, що рівень задоволеності студентів проведенням занять в умовах карантинних обмежень прямо залежить від зацікавленості, відповідальності, професіоналізму викладача та активного зворотного зв'язку «студент-викладач». Відсутність зазначених складових знижує зацікавленість студентів у навчанні і провокує негативні наслідки. Інформаційно-комунікаційні технології та інтерактивність урізноманітнюють, зацікавлюють та мотивують студентів до пізнання, тому викладачі намагаються активізувати та зацікавити студентів, впроваджуючи різні засоби дистанційного навчання.

Дистанційна освіта має ряд переваг та недоліків. Було виявлено, що дистанційне навчання як альтернативна форма освітнього процесу не може в повній мірі замінити традиційну очну форму навчання. Але грамотне використання засобів дистанційного навчання дозволяє урізноманітнити освітній процес, зробити його значно цікавішим та ефективнішим.

Перспективи подальших досліджень полягають у проведенні аналізу ефективності використання різних засобів дистанційного навчання в освітньому процесі закладів вищої освіти фізкультурного профілю та у розробці практичних рекомендації щодо їх впровадження.

Конфлікт інтересів. Автори заявляють, що немає конфлікту інтересів, який може сприйматися як такий, що може завдати шкоди неупередженості статті.

Джерела фінансування. Ця стаття не отримала фінансової підтримки від державної, громадської або комерційної організації.

\section{Список посилань}

1. Алексєєва І. А. (2017), «Основні елементи дистанційного курсу «Спортивна метрологія» при підготовці фахівців з фізичної культури і спорту», Науково-методичні основи використання інформаційних технологій в галузі фізичної культури та спорту, № 1, С. 12-15.

2. Ашанін В. С., Єгорова О. В., Філенко Л. В. (2018), Інформаційно-комунікаційні системи у фізичному вихованні та спорті: навч. посіб. Харків: ХДАФК, 164 с.

3. Єгорова О. В. (2018), «Використання продуктів компанії Google для вдосконалення професійної підготовки фахівців у сфері фізичної культури та спорту», Науково-методичні основи використання інформаційних технологій в галузі фізичної культури і спорту, № 2, С. 35-38.

4. Жерновнікова Я. В. (2018), «Шляхи впровадження інформаційних технологій в процес фізичного виховання», Науковий часопис НПУ імені М.П. Драгоманова. Серія 15: Науково-педагогічні проблеми фізичної культури (фізична культура і спорт), № 5 (99)18, С. 97-99.

5. Жерновнікова Я. В., Пятисоцька С. С. (2020), «Особливості використання платформи Моodle під час вивчення дисципліни «Інформатика», Науково-методичні основи використання інформаційних технологій в галузі фізичної культури і спорту, № 4, C. $26-29$.

6. Організація дистанційного навчання в школі: методичні рекомендації. URL:https://mon.gov.ua/storage/app/media/ zagalna\%20serednya/metodichni\%20recomendazii/2020/metodichni\%20recomendazii-dustanciyna\%20osvita-2020.pdf

7. Шандригось Г.А., Шандригось В.І., Ладика П.І. (2015), «Дистанційне навчання в системі підготовки фахівців з фізичної культури і спорту», Науковий часопис НПУ імені М.П. Драгоманова. Серія 15: Науково-педагогічні проблеми фізичної культури (фізична культура і спорт), № 5 (61) 15, С. 270-273.

8. Шаповалов М., Сушко Р. (2021), «Особливості організації дистанційного навчання як форми проведення уроків фізичної культури», Слобожанський науково-спортивний вісник, № 1 (81), С. 42-46.

9. Osipov A.Y., Kudryavtsev M.D., Galimova A.G., Plotnikova I.I., Skurikhina N.V. (2020), «How can Distance Learning be Used in the Physical Education of Students», Revista Romвnească pentru Educaţie Multidimensională, 12 (2Sup1), pp. 77-85.

10. Rembach O., Liybich O., Antonenko M., Kovalenko V., Valieiev R. (2019), «University students' satisfaction: The impact of computer-mediated blended learning», Revista Rombnească pentru Educaţie Multidimensională, 11 (4S1), pp. 221-241.

11. Zhelezniakova E., Silichova T. (2020), «Use of distance courses in the study of economic and mathematical cycle disciplines in the process of preparing economists in higher education institutions», Pedagogical sciences: theory, history, innovation technologies, 2 (96), pp. 34-43.

Стаття надійшла до редакції: 27.07.2021 р.

Опубліковано: 31.08.2021 p. 


\begin{abstract}
Аннотация. Елена Басенко, Ирина Алексеева, Яна Алексенко, Яна Жерновникова. Особенности использования средств дистанционного обучения в высших учебных заведениях физкультурного профиля в условиях карантинных ограничений. Цель: проанализировать организационные и методические особенности использования информационных средств дистанционного обучения в подготовке будущих специалистов физической культуры и спорта. Материал и методы: для реализации поставленной цели нами были использованы следующие методы исследования: анализ научно-методической литературы; ресурсы сети Интернет; опрос с помощью Google-форм; анализ, синтез и обобщение полученных данных; методы математической статистики. В опросе принимали участие 93 студента первого, второго и третьего курсов дневной формы обчения Харьковской государственной академии физической культуры. Результаты: рассмотрены особенности организации учебного процесса в условиях карантина с использованием средств дистанционного обучения в высших учебных заведениях физкультурного профиля. Проведённый онлайн-опрос студентов выявил их отношение к дистанционной, очной и смешанной формам обучения; их предпочтения и обеспеченность различными электронными ресурсами, программами, инструментами информационных коммуникаций, которые использовались преподавателями в учебном процессе. Проанализированы возможные сложности и значимость для студентов преимуществ дистанционного обучения. Выводы: исследование показало, что преподаватели академии за короткий срок и в сложных условиях освоили цифровые инструменты, коммуникационные ресурсы и дистанционные платформы, которые не использовали ранее. Онлайн-опрос показал, что мнение студентов по отношению к дистанционной, очной и смешанной формам обучения разделилось. Результаты исследования подтвердили мнение других ученых о том, что дистанционное обучение, как альтернативная форма образовательного процесса, не может в полной мере заменить традиционную очную форму обучения, а использование средств дистанционного обучения позволяет разнообразить образовательный процесс, сделать его значительно интереснее и эффективнее.
\end{abstract}

Ключевые слова: дистанционное обучение, студенты, онлайн-занятия, средства дистанционного обучения, программы для видеоконференций, инструменты электронного обучения.

Abstract. Olena Basenko, Iryna Aleksieieva, Yana Aleksienko, Yana Zhernovnikova. Features of the use of distance learning tools in higher educational institutions of physical culture in the conditions of quarantine restrictions. Purpose: to analyze the organizational and methodological features of the use of informational means of distance learning in the training of future specialists in physical culture and sports. Material and methods: for the implementation of this goal, we used the following research methods: analysis of scientific and methodological literature; Internet resources; a survey using Google Forms; analysis, synthesis and generalization of the data obtained; methods of mathematical statistics. 93 students of the first, second and third courses of the daytime department of the Kharkiv State Academy of Physical Culture took part in the survey. Results: the features of the organization of the educational process in quarantine conditions using distance learning tools in higher educational institutions of physical culture are considered. An online survey of students revealed their attitude to distance, full-time and mixed forms of education; their preferences and the provision of various electronic resources, programs, information communication tools that were used by teachers in the educational process. Possible difficulties and the significance of the benefits of distance learning for students are analyzed. Conclusions: the study showed that the academy teachers in a short time and in difficult conditions mastered digital tools, communication resources, and remote platforms that they had not used before. An online survey showed that students' opinions on distance learning, full-time and blended learning were divided. The results of the study confirmed the opinion of other scientists that distance learning as an alternative form of the educational process cannot fully replace the traditional full-time form of education, and the use of distance learning tools makes it possible to diversify the educational process, make it much more interesting and effective.

Keywords: distance learning, students, online classes, distance learning tools, video conferencing software, e-learning tools.

\title{
References
}

1. Aleksyeyeva, I. A. (2017), «The main elements of the distance course «Sports Metrology» in the training of specialists in physical culture and sports», Naukovo-metodychni osnovy vykorystannya informatsiynykh tekhnolohiy v haluzi fizychnoyi kul'tury ta sportu, No. 1, pp. 12-15 (in Ukr.).

2. Ashanin, V. S., Yehorova, O. V., Filenko, L. V. (2018), Informatsiyno-komunikatsiyni systemy u fizychnomu vykhovanni ta sporti: navch. posib. Kharkiv. KHDAFK, 164 p. (in Ukr.).

3. Yehorova, O. V. (2018), «Use Google products to improve the training of physical education and sports professionals», Naukovo-metodychni osnovy vykorystannya informatsiynykh tekhnolohiy v haluzi fizychnoyi kul'tury i sportu, No. 2, pp. 35-38 (in Ukr.).

4. Zhernovnikova, Y. V. (2018), «Ways of introduction of information technologies in the process of physical education», Naukovyi chasopys NPU imeni M.P. Drahomanova. Seriya 15: Naukovo-pedahohichni problemy fizychnoyi kul'tury (fizychna kul'tura i sport), No. 5 (99)18, pp. 97-99 (in Ukr.).

5. Zhernovnikova, Y. V., Pyatysots'ka, S. S. (2020), «Features of using the Moodle platform when studying the discipline "Computer Science»", Naukovo-metodychni osnovy vykorystannya informatsiynykh tekhnolohiy v haluzi fizychnoyi kul'tury i sportu, No. 4, pp. 26-29 (in Ukr.).

6. Orhanizatsiya dystantsiynoho navchannya v shkoli: metodychni rekomendatsiyi. Access at: https://mon.gov.ua/storage/app/ media/zagalna\%20serednya/metodichni\%20recomendazii/2020/metodichni\%20recomendazii-dustanciyna\%20osvita-2020.pdf (in Ukr.).

7. Shandryhos', H. A., Shandryhos', V. I., Ladyka, P. I. (2015), "Distance learning in the system of training specialists in physical culture and sports", Naukovyi chasopys NPU imeni M.P. Drahomanova. Seriya 15: Naukovo-pedahohichni problemy fizychnoyi kul'tury (fizychna kul'tura i sport), No. 5 (61) 15, pp. 270-273 (in Ukr.).

8. Shapovalov, M., Sushko, R. (2021), «Features of the organization of distance learning as a form of physical education lessons», Slobozhans'kyy naukovo-sportyvnyy visnyk, No. 1 (81), pp. $42-46$ (in Ukr.).

9. Osipov, A. Y., Kudryavtsev, M. D., Galimova, A. G., Plotnikova, I. I., Skurikhina, N. V. (2020), «How can Distance Learning be Used in the Physical Education of Students», Revista Rombnească pentru Educaţie Multidimensională, No. 12 (2Sup1), pp. 77-85 (in Eng.).

10. Rembach, O., Liybich, O., Antonenko, M., Kovalenko, V., Valieiev, R. (2019), «University students' satisfaction: The impact of computer-mediated blended learning», Revista Romвnească pentru Educaţie Multidimensională, No. 11 (4S1), pp. 221 -241 (in Eng.).

11. Zhelezniakova, E., Silichova, T. (2020), «Use of distance courses in the study of economic and mathematical cycle disciplines in the process of preparing economists in higher education institutions", Pedagogical sciences: theory, history, innovation technologies, No. 2 (96), pp. 34-43 (in Eng.). 


\section{СЛОБОЖАНСЬКИЙ НАУКОВО-СПОРТИВНИЙ ВІСНИК}

\section{Відомості про авторів / Information about the Authors}

Басенко Олена Вікторівна: к.фіз.вих.; Харківська державна академія фізичної культури: вул. Клочківська 99, м. Харків, 61058, Україна.

Басенко Елена Викторовна: к.физ.восп.; Харьковская государственная академия физической культуры: ул. Клочковская 99, г. Харьков, 61058, Украина.

Olena Basenko: PhD (Physical Education and Sport); Kharkiv State Academy of Physical Culture: Klochkovskaya str. 99, Kharkiv, 61058, Ukraine.

ORCID: https://orcid.org/0000-0001-7660-559X

E-mail: e.v.basenko@gmail.com

Алексєєва Ірина Анатоліївна: Харківська державна академія фізичної культури: вул. Клочківська 99, м. Харків, 61058, Україна.

Алексеева Ирина Анатолиевна: Харьковская государственная академия физической культуры: ул. Клочковская 99, г. Харьков, 61058, Украина.

Iryna Aleksieieva: Kharkiv State Academy of Physical Culture: Klochkovskaya str. 99, Kharkiv, 61058, Ukraine.

ORCID: https://orcid.org/0000-0003-2709-2040

E-mail: irina.alekseyeva62@gmail.com

Алексєнко Яна Валеріївна: Харківська державна академія фізичної культури: вул. Клочківська 99, м. Харків, 61058, Україна. Алексенко Яна Валерьевна: Харьковская государственная академия физической культуры: ул. Клочковская 99, г. Харьков, 61058, Украина.

Yana Aleksienko: Kharkiv State Academy of Physical Culture: Klochkovskaya str. 99, Kharkiv, 61058, Ukraine.

ORCID: https://orcid.org/0000-0002-3339-200X

E-mail: aleksenko.yv@gmail.com

Жерновнікова Яна Вікторівна: к.пед.н.; Харківська державна академія фізичної культури: вул. Клочківська 99, м. Харків, 61058, Україна.

Жерновникова Яна Викторовна: к.пед.н.; Харьковская государственная академия физической культуры: ул. Клочковская 99, г. Харьков, 61058, Украина.

Yana Zhernovnikova: PhD (Pedagogical Science); Kharkiv State Academy of Physical Culture: Klochkovskaya str. 99, Kharkiv, 61058, Ukraine.

ORCID: https://orcid.org/0000-0002-5574-8652

E-mail: zhernovnicova@gmail.com 